\title{
Lagrangian process attribution of isotopic variations in near-surface water vapour in a 30-year regional climate simulation over Europe
}

Marina Dütsch et al.

Correspondence to: Marina Dütsch (marina.duetsch@env.ethz.ch)

The copyright of individual parts of the supplement might differ from the CC BY 4.0 License. 


\section{Contents of this file}

- Figures S1 to S4

\section{Description}

- Figures S1 and S2 show the contributions of the processes to the monthly and yearly anomalies of $\delta^{2} \mathrm{H}$

- Figures S3 and S4 show the contributions of the processes to the monthly and yearly anomalies of deuterium excess. 

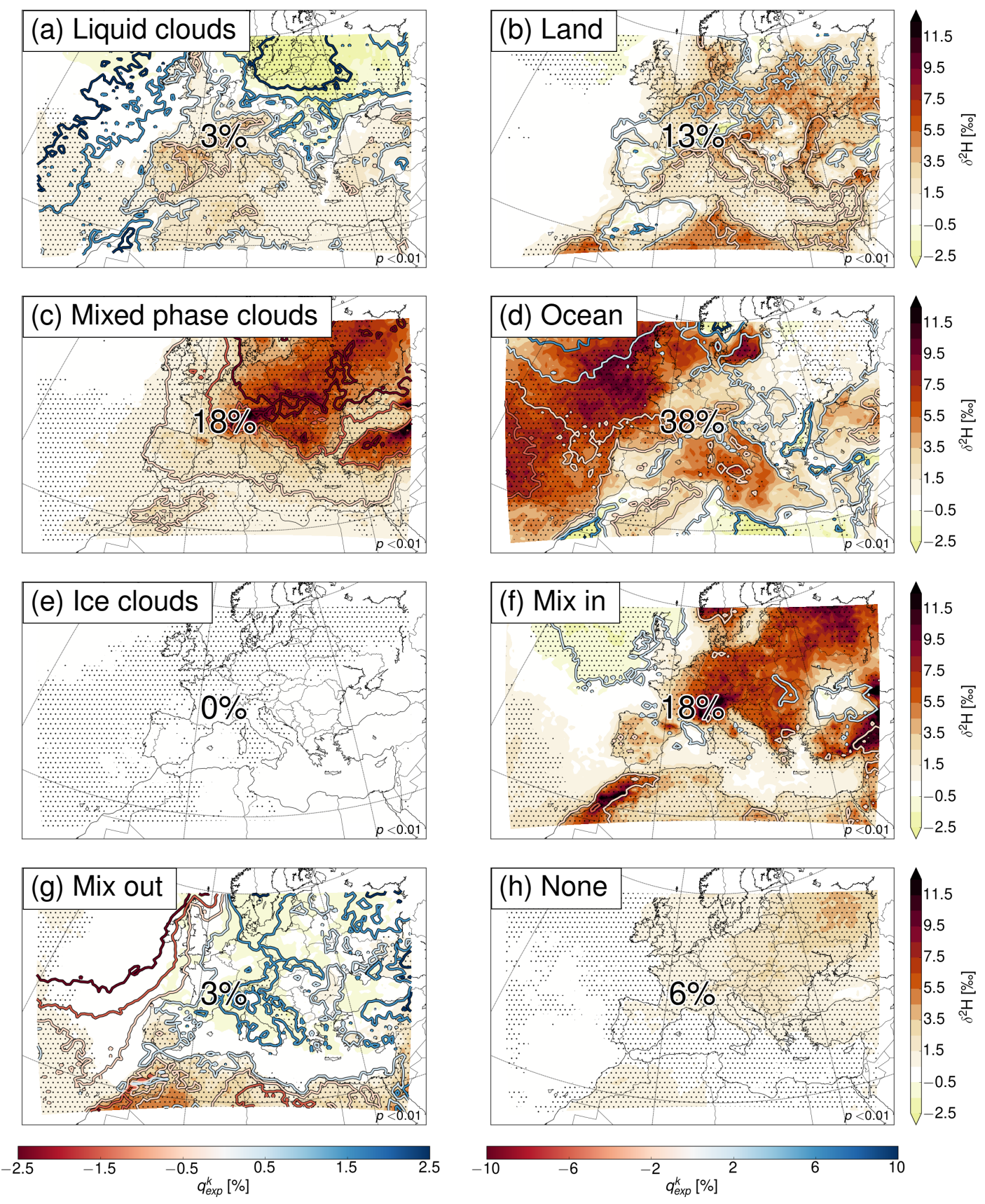

Figure S1: Contributions of the processes to the monthly $\Delta \delta^{2} \mathrm{H}$ in Figure $10 \mathrm{c}$. The contours show the difference in $q_{e x p}^{k}$ (see Equations 10 and 11) between the high and low anomaly months in \%. Stippling indicates areas where $p<0.01$. Note the different colour scales for $q_{e x p}^{k}$ between the left and right hand side. 

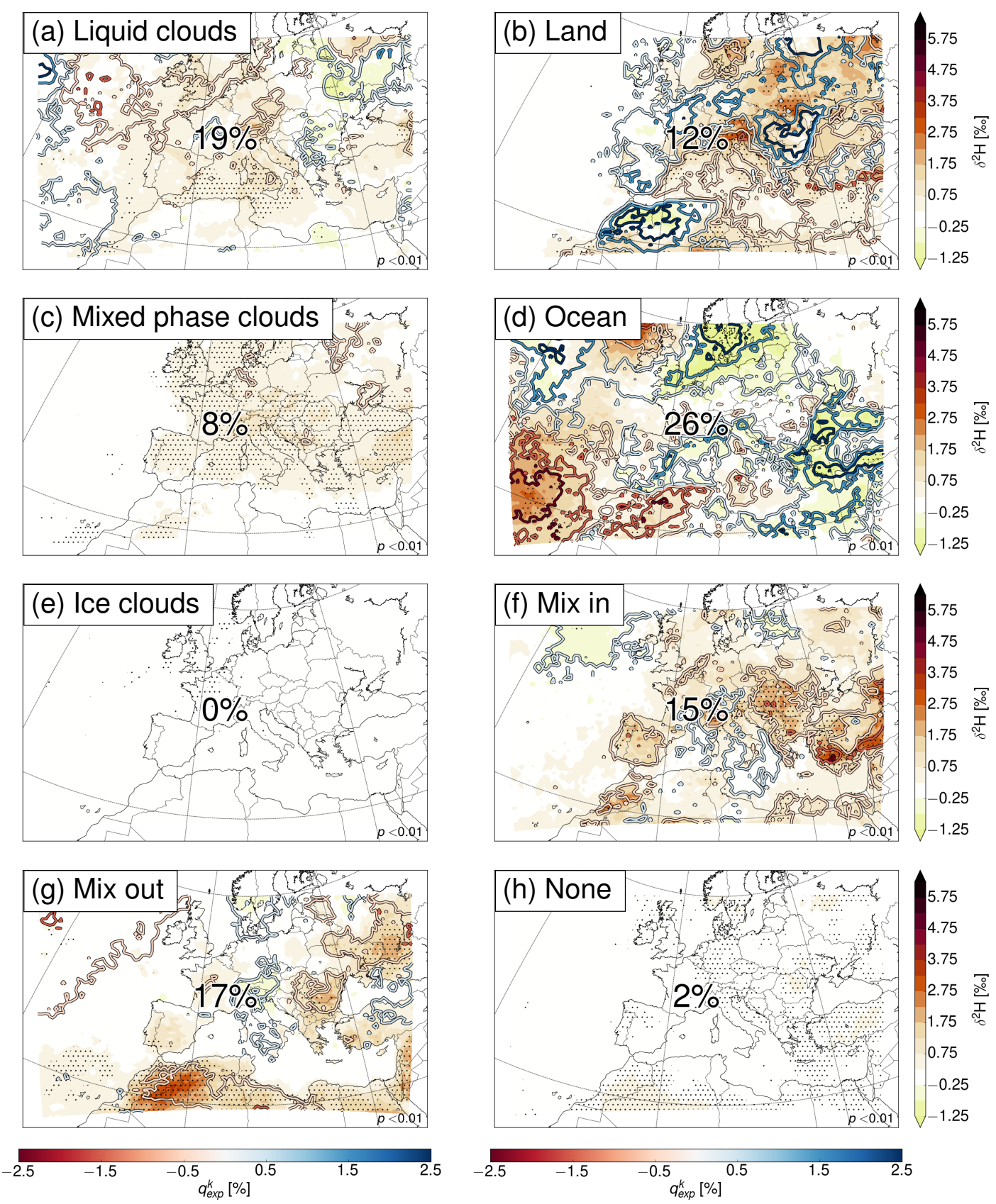

Figure S2: Contributions of the processes to the yearly $\Delta \delta^{2} \mathrm{H}$ in Figure $10 \mathrm{c}$. The contours show the difference in $q_{e x p}^{k}$ (see Equations 10 and 11) between the high and low anomaly years in \%. Stippling indicates areas where $p<0.01$. 

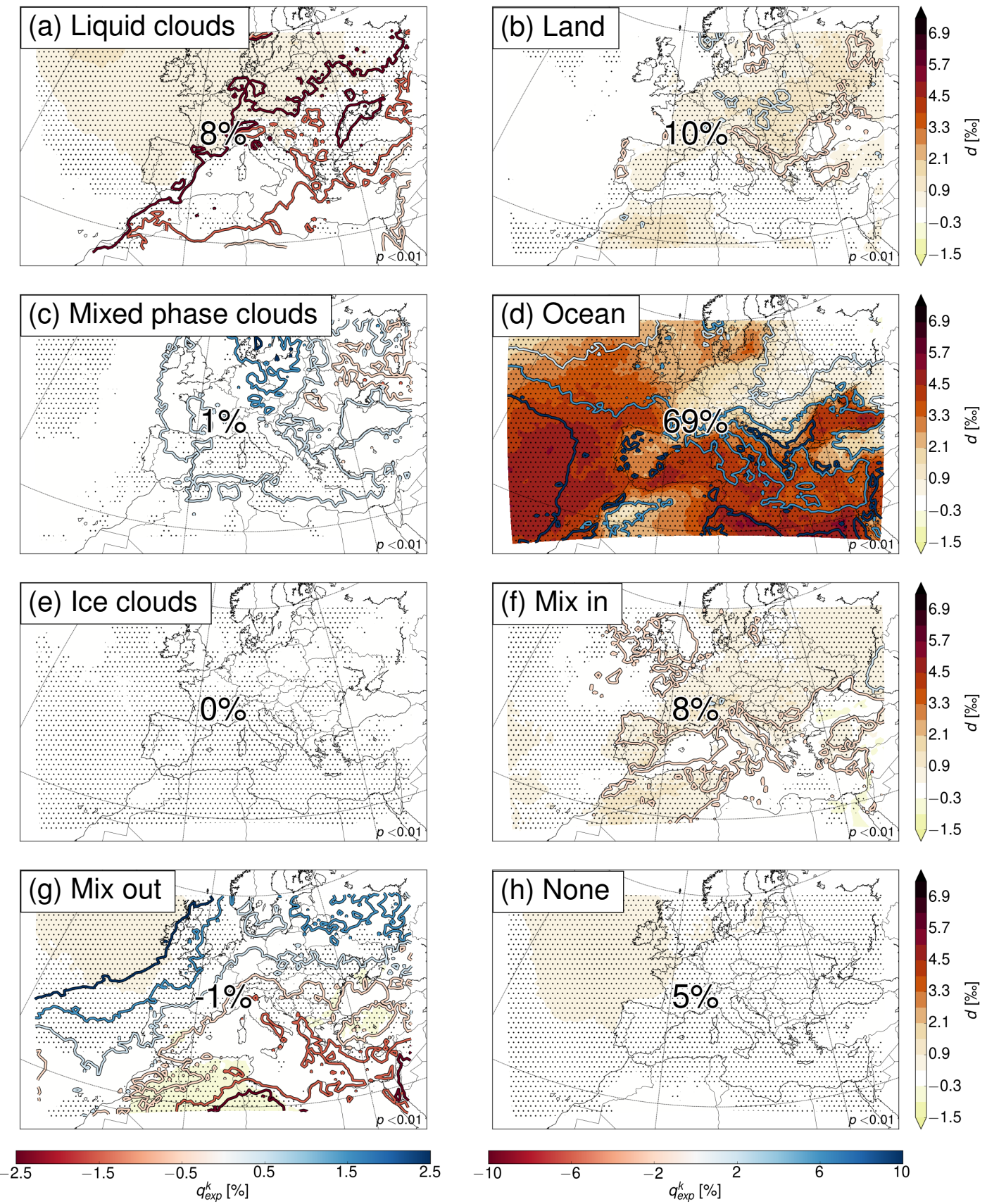

Figure S3: Contributions of the processes to the monthly $\Delta d$ in Figure $12 \mathrm{c}$. The contours show the difference in $q_{e x p}^{k}$ (see Equations 10 and 11) between the high and low anomaly months in \%. Stippling indicates areas where $p<0.01$. Note the different colour scales for $q_{e x p}^{k}$ between the left and right hand side. 

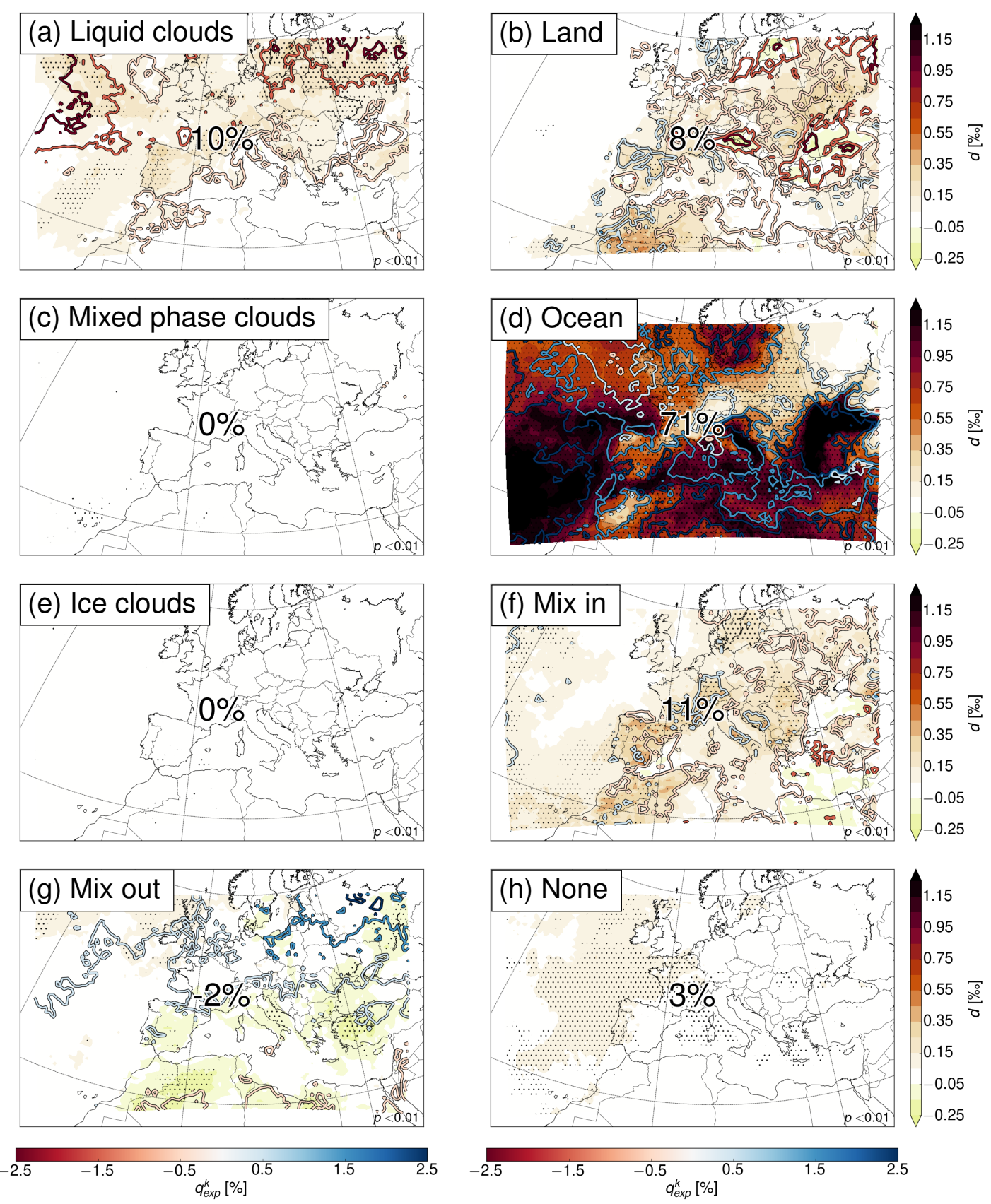

Figure S4: Contributions of the processes to the yearly $\Delta d$ in Figure $12 \mathrm{c}$. The contours show the difference in $q_{e x p}^{k}$ (see Equations 10 and 11) between the high and low anomaly years in \%. Stippling indicates areas where $p<0.01$. 